\title{
Comunicación

\section{Una nueva socialité llegó: historia de la recepción televisiva en la ciudad de Aguascalientes}

\author{
MARÍA REBECA PADILLA DE LA TORRE*
}

El estudio de la llegada y la trayectoria de la televisión en las vidas familiar y social permite comprender el proceso a través del cual una comunidad tradicional se configura como audiencias, y las implicaciones que conlleva en términos de la relación entre los espacios público y privado. Este análisis histórico de las prácticas culturales de la recepción o consumo televisivo posibilita el dar cuenta de cómo la televisión se vincula con el cambio social, con las formas de producir sentido $\mathrm{y}$, en general, las modalidades emergentes de la relación entre la comunicación, la cultura y la historia.

PALABRAS CLAVE: historia de la recepción televisiva, estudio cualitativo de audiencias, historias de familia, investigación hemerográfica.
The study of the arrival and the development of television in family and social life allows the comprehension of the process through which a traditional community turns into audiences and the implications it means in the relations between public and private space. This historical analysis of the cultural practices of television reception or consumption makes possible the account of how television is bond to social change, ways of producing meaning, and the resulting manners of the relation between communication, culture and history.

KEY WORDS: television reception history, qualitative study of audiences, family histories, newspaper library research.

* Universidad Autónoma de Aguascalientes.

Correo electrónico: mpadilla@correo.uaa.mx. 
El nueve de diciembre de 1957, en el periódico El Sol del Centro de Aguascalientes, aparece en las páginas de sociales la señorita Hilda Muñoz viendo un programa de televisión en ocasión de su cumpleaños. ¿Qué trascendencia podría tener esa foto en el marco de los estudios del consumo televisivo? Esa fotografía ilustra el enlazamiento de dos narrativas, con el fin de recuperar la historia cultural de la televisión en mi ciudad natal: tanto la historia social narrada a través de un periódico, en los inicios de la TV en esta localidad, como las historias familiares que cuentan la llegada de la TV a su vida familiar, y cómo paulatinamente sus miembros se convirtieron en audiencias televisivas.

La historia promete contar no sólo lo que pasó y cómo, sino a través de la interpretación de los datos y las narrativas comprender preguntas que surgen sobre los cambios, la causalidad y los procesos en las relaciones sociales y humanas. El sentido de la contingencia y lo circunstancial a través de la historia permite enriquecer el sentido de lo actual (Corner, 2003). Por ello la inquietud por indagar cómo los aguascalentenses nos configuramos como públicos frente al televisor remitió no sólo a la etnografía del consumo televisivo, sino, además, a la diacronía de esta práctica. La historia de la TV puede abordarse según Corner desde cinco aspectos claves: el estudio de la TV como institución y organización, el estudio de su producción, de las representaciones y formatos en sus contenidos; como un fenómeno sociocultural con relación a la esfera pública y a la cultura popular; con el cambio en la cotidianidad y valores en la vida familiar y como un objeto tecnológico en sí. Este estudio aborda las tres últimas posibilidades, creando un marco conceptual entre el estudio de la comunicación, la cultura y la historia.

La recuperación histórica de la recepción de la comunicación social es una perspectiva poco explorada en nuestro país. Se ha recuperado la historia de los medios desde su institucionalidad o desde su carácter de empresa o industria, pero poco sobre cómo se recibieron los medios por primera vez en las familias (Van Zoonen \& Wieten, 1994), cómo se insertaron en lo cotidiano y cómo poco a poco la sociedad, en este caso la aguascalentense, se constituyó en parte de los extensos públicos televisivos. El comprender a las tecnologías de comunicación, no como instituciones aisladas, sino conjugándolas con las prácticas sociales y 
las formas culturales, permitió definir cómo la comunicación ha sido determinante en el desarrollo social y, a la vez, cómo lo social ha determinado el desarrollo de los medios de comunicación (Dahl, 1994; Gómez Mompart, 1995).

El sustento teórico de esta investigación parte de los estudios cualitativos sobre la recepción o consumo televisivo, los cuales pretenden proporcionar elementos que nos permitan reflexionar sobre cómo nos constituimos en ese público y cómo serlo nos ha configurado y nos sigue interpolando con relación a cómo comprendemos nuestro entorno y nos relacionamos como sociedad (Orozco, 2000). Varios autores (Gubern, R., 2000; Jensen, K., 1995; Martín-Barbero, J., 2001; Thompson, J., 1998; Tufte,T.,1999.) coinciden en que los nuevos itinerarios de la investigación, en el campo de la comunicación, deben interrogar las transformaciones que han significado la mediación de los medios de comunicación en nuestras vidas.

Martín-Barbero (2001) argumenta que no es posible hacer a un lado la cultura comunicacional, debido a que al introducirse el espesor mediático en lo social ha reconfigurado las relaciones entre sociedad, cultura y política. La revolución tecnológica no introduce sólo máquinas, sino un nuevo modo de relación entre los procesos simbólicos que constituyen lo cultural. La recuperación del sentido que tiene ver u oír televisión o radio es diferente a indagar la significación del mensaje. El estudio del consumo amplía la perspectiva de la relación del texto y las audiencias para analizar a la comunicación masiva con la vida cotidiana y la cultura. Varios autores coinciden en que los nuevos itinerarios de la investigación deben interrogar las transformaciones que han significado la mediación de los medios de comunicación en nuestras vidas; ¿cómo es que a través de ellos conocemos, hacemos, representamos y vemos?, ¿cómo se vive el espacio doméstico y el público?, ¿cómo se relacionan con los modos del ejercicio del poder, el control social, las expectativas, los retos éticos y las búsquedas morales? (Gubern, 2000).

Los estudios sobre el consumo cultural son necesarios porque se carece de datos básicos sobre ¿qué pasa con los públicos, los receptores, las audiencias? Para García Canclini se requiere una comprensión más profunda de la relación de los bienes culturales en la vida cotidiana. 
El estudio del consumo es un lugar estratégico para repensar el tipo de sociedad que deseamos, el lugar que tocará a cada sector, el papel del poder público como garante de que el interés público no sea desperdiciado. Conocer lo que ocurre en los consumos es interrogarse sobre la eficacia de las políticas, sobre el destino de lo que producimos entre todos, sobre las maneras y las proporciones en que participamos en la construcción social del sentido. (García Canclini: 1993: 42).

Comprender integralmente y reflexionar sobre el consumo significa indagar en las prácticas cotidianas en donde se interioriza la desigualdad social, es el lugar en donde se da la conciencia de lo posible en cada vida, de lo alcanzable e inalcanzable, lugar en donde se impugnan esos límites y donde se expresan los deseos, donde se subvierten los códigos y además donde se da el placer y el goce. El consumo no sólo es la reproducción de fuerzas, sino también el lugar en dónde se producen sentidos. El consumo entonces se define como

el conjunto de procesos de apropiación y usos de productos en los que el valor simbólico prevalece sobre los valores de uso y de cambio, o donde al menos estos últimos se configuran subordinados a la dimensión simbólica" (García Canclini: 1993: 34).

Estos argumentos han complejizado la comprensión de las audiencias o los públicos, al no limitarse a preguntar ¿quiénes son los públicos, sino qué es el público? El estudio que consistía en describir numéricamente y en categorías sociales a las audiencias, ahora se propone en otros términos; se estudia a los públicos para comprender cómo al convertirse en tales se modelan comportamientos que regulan las interacciones, legitiman las institucionalidades y el poder e incluso la misma relación con los medios masivos.

María Cristina Mata (2001:183-200) se basa en aportaciones de Gabriel Tarde y Walter Benjamín para definir tres principios rectores en el estudio de la sociedad moderna como una sociedad de los públicos:

- El modo en que los individuos son interpelados en lo individual y colectivo, desde los medios, para constituirse como público de los mismos y su constitución empírica. 
- Las relaciones entre ese sistema de interpelación y las condiciones de vida particulares de diversos grupos sociales.

- Las consecuencias simbólicas y prácticas que tienen las condiciones y discursos que prefiguran públicos específicos.

El estudio del consumo de los medios masivos de comunicación se conecta con los debates teóricos más amplios en torno a las prácticas y políticas del consumo cultural en las que Bourdieu (1984) ha establecido un importante paradigma para comprender los patrones o prácticas del consumo cultural, en donde se reproduce o normaliza en las clases un modelo de normas y valores que permite poco espacio para el cambio social. Por otra parte, los estudios críticos y cualitativos del consumo de medios han asumido la dualidad entre la "creatividad" y la "constricción" de los públicos. Se acepta que la agencia interpretativa de las audiencias está sujeta tanto a sus propios límites como a los establecidos por los procesos de producción de los contenidos; sin embargo, busca la formulación de teorías y metodologías que problematicen ambos aspectos para proponer una teoría adecuada de la "creatividad cultural constreñida" y un método interpretativo cultural que incluya dimensiones de espacio y tiempo.

La etnografía del consumo de medios asume los debates en torno al poder de los textos mediáticos para determinar la producción de sentidos y ha articulado estas preguntas con los diversos géneros y "gustos" entre el público. Ha enfatizado el estudio del consumo en el contexto familiar y en escenarios cotidianos como la escuela y el barrio. ${ }^{1}$

Shaun Moores (1996) ubica los intereses de los estudios cualitativos de las audiencias que han enfatizado la etnografía del consumo de medios en cuatro rubros: a) una intervención en los debates en torno al poder de los mensajes mediáticos para determinar los significados que producen sus audiencias; b) el intento por articular los diversos géneros mediáticos con diversos "gustos" o preferencias del público, desde la

1 El análisis y la crítica al estudio del consumo de medios ha sido abordado por varios autores: Ang, I., 1996; Crawford, P. y Hafsteinsson, S., 1996; Lull, J., 1992:50-57; Martín-Barbero, J., 1999; Moores, S., 1996; Morley, D., 1986; Nightingale, V., 1999, Orozco, G., 2000; Seiter, E, 1999; Vassallo de Lopes, M.,1995. 
perspectiva de que son construidos culturalmente; c) el interés en la dinámica social del consumo de medios situado en el contexto doméstico y en las relaciones familiares, y d) la diversificación de representaciones, usos y sentidos que suscitan el espectro de las tecnologías comunicativas en los hogares.

En esta investigación se retoman estas miradas teóricas para diseñar una metodología que permitió describir, de manera específica, cómo en el seno de la familia se ha dado el consumo televisivo a través de tres generaciones y los usos sociales que se les han otorgado, y cómo estos han cambiado a lo largo del tiempo en la historia familiar. Por ejemplo, ¿qué espacios ocupó y qué significó la televisión en la vida familiar en los últimos cincuenta años? No se llevó a cabo un análisis de la interpretación de los contenidos de los géneros televisivos, ni la descripción detallada de cómo se ve la televisión en la rutina familiar, sino el uso social que se le ha dado a este medio con relación a los sentidos que adquirió su consumo a lo largo de la historia familiar.

En América Latina, los estudios etnográficos de los medios se han guiado por la teoría de la mediación sociocultural de Martín-Barbero (1987). Las mediaciones se comprenden como " el conjunto de influencias que estructuran, organizan y reorganizan la comprensión de la realidad en la cual vive la audiencia, por lo cual además poseen el poder para dar valor y significado a esta realidad". Martín-Barbero argumenta que algunas de las mediaciones más representativas son la vida cotidiana familiar, los usos sociales de los medios y la competencia cultural para comprenderlos desde la visión del género; por ejemplo; en televisión, las telenovelas (idem).

En México, las mediaciones han sido abordadas en el ámbito de la "televidencia" por Guillermo Orozco, quien la define como

la multidimensionalidad de las interacciones que movilizan las diversas espacialidades y temporalidades desde las que el sujeto individual y colectivo procesa los discursos y las narrativas, las mitologías y los imaginarios del telever.

Las mediaciones han sido clasificadas por este autor con el objetivo de enfrentar la difícil labor que significa comprender el consumo televi- 
sivo en este marco. A partir de estas teorías se establecieron los criterios necesarios para comprender e interpretar las posibles combinaciones y juegos que estas influencias o mediaciones ejercen en las audiencias televisivas (Orozco, 2000).

Estos lugares de mediación se asumieron para explorar los usos de la televisión, en donde habla no sólo la clase social, sino también sus competencias culturales frente a los géneros televisivos, los imaginarios que se han configurado y el cambio social. La propuesta de MartínBarbero consiste en dar cuenta, a partir precisamente de los relatos o historias familiares que nos cuentan, de la historia de la presencia de la televisión en la vida de las personas.

El estudio del consumo (García Canclini, 1993) amplía la perspectiva de la relación del texto y las audiencias para analizar a la comunicación masiva inserta en la vida cotidiana y la cultura. En este sentido, la televisión adquiere otra dimensión, no se comprende sólo como un vehículo que trasmite determinados contenidos a través de su programación, sino como un objeto que se sitúa en el escenario social, y más allá de una mercancía de cambio, cobra vida propia (Appadurai, 1991; Spigel, 2001).

Con base en estos argumentos el problema de este estudio se centró en el consumo de los medios de comunicación, en general, y de la televisión en particular, desde la perspectiva cultural, lo cual implicó develar qué significa para los individuos hacer uso de la televisión en sus vidas. La manera en la cual se abordó el consumo se dio en el marco de la cotidianidad familiar, el cual constituye una de las principales mediaciones que perfilan el consumo, además de los usos sociales y la competencia cultural de las personas frente a los medios (Covarrubias, 1994; Guadarrama, 2000; Navarro, 2003; Padilla, 2004). Como ya se explicó, esta investigación añade la dimensión diacrónica, en donde a través de la recuperación de historias familiares y una búsqueda en la prensa de la década de 1950, se reconstruye la historia de las audiencias en la ciudad de Aguascalientes.

La metodología consistió en integrar la historia de tres familias, describiendo su cotidianidad antes de la llegada de la TV, los primeros contactos con el aparato, la primera TV que se compró y cómo cada generación la ha integrado a sus estilos de vida. Para ello, se partió de 
las metodologías trabajadas por González (1998), Jacks (2001) y Young (1996). Los criterios para elegir las familias fueron: que hubieran vivido en el Estado desde 1950 a la fecha -que es la década en la cual la TV comienza a trasmitir en el país-; que contarán por lo menos con un informante para cada etapa que se investigaba: de 1950-1965, generación A (informantes mayores de 65 años); de 1965-1980, generación B (informantes entre 35 y 65 años) y de 1980 a la fecha, generación C (informantes entre 10 y 35 años); y que la familia contara con los indicadores que se establecieron para ubicarla en determinado estrato socioeconómico: bajo, medio y alto. ${ }^{2}$ Se seleccionó a uno o dos miembros de la familia, de cada generación, que tuvieran mayor información y capacidad de narrar. Posteriormente, se realizaron 17 historias de familia más, ubicadas en tres diferentes estratos socioeconómicos (6 en el estrato socioeconómico bajo, 7 en el medio y 4 en el alto) con el fin de corroborar las categorías que surgieron de la primera etapa del trabajo de campo. ${ }^{3} \mathrm{La}$ lógica cualitativa de esta investigación no pretendió lograr una muestra representativa mediante una cobertura amplia, sino comprobar las categorías y dimensiones encontradas bajo el principio de la búsqueda de la redundancia, en los hallazgos, para verificar su validez.

Además de integrar una narrativa que surgiera de las historias de familias, se siguió la sugerencia de Young (1996), en el sentido de complementar estas historias con una narrativa más amplia, recuperando el contexto social en el cual transcurren. Por ello, se buscó la historia de la TV en un periódico de la localidad, El Sol del Centro, a partir de cinco años antes de la llegada de la TV y de manera detallada durante la década de 1950 a $1960.4^{4}$ A partir de la búsqueda hemerográfica, se

2 No se pretende en este reporte distinguir diferencias entre estos estratos; sin embargo, en la muestra de familias se consideraron tres diferentes estratos con el fin de integrar una mejor representatividad y diversificación, aunque el criterio es claramente de casos y de una perspectiva cualitativa.

3 Esta etapa fue trabajada a manera de taller con los alumnos del octavo semestre, en la materia de televisión educativa y cultural de la carrera de comunicación y medios masivos, en la Universidad Autónoma de Aguascalientes.

4 Considero que de manera ideal se debió trabajar la misma diacronía que contempló las historias familiares desde antes de 1950, cuando se tienen las 
identificaron dos importantes personajes que protagonizaron los inicios y la consolidación de la señal televisiva en la ciudad: don Pedro Rivas y el Ing. Roberto Martínez; las entrevistas con ambos permitieron una mejor comprensión de las notas periodísticas para recuperar la narrativa social más allá del ámbito privado. 5

\section{LA LLEGADA DE LA TELEVISIÓN A AGUASCALIENTES}

En 1946, el periódico da cuenta por primera ocasión de la TV como un nuevo invento muy costoso y por ello con pocas oportunidades de insertarse en los hogares mexicanos. 6 Después de varios años de oír de la TV como una novedad lejana a su realidad, en 1952 se inician gestiones por parte de los empresarios radiofónicos por traer una antena repetidora al estado, con fin de recibir con calidad las señales de TV producida en el Distrito Federal; además, en aquel tiempo vislumbraban la probabilidad de unir esfuerzos para constituir la empresa Televisión del Centro, y crear así una televisora con producción propia. ${ }^{7}$ Sin embargo,

primeras noticias y encuentros con la TV hasta la fecha; sin embargo, las limitantes de recursos y tiempo para esta investigación no lo permitió.

5 Se entrevistó a don Pedro Rivas, empresario radiofónico que realizó las primeras trasmisiones experimentales en la ciudad y participó en las primeras iniciativas por instalar la infraestructura de retrasmisión en Aguascalientes, así como al Ing. Roberto Martínez, que protagonizó la etapa de consolidación de la señal televisiva, la cual se complicó debido a la falta de un liderazgo y compromiso de parte del gobierno del Estado por regular las inversiones que correspondían tanto al sector público como al privado.

6 Periódico El Sol del Centro, 15 de enero de 1946. Debido a que esta investigación sólo revisó este periódico local, en lo subsecuente sólo se hará referencia al día en que apareció la nota o notas a las que se hacen referencia en el texto, asumiendo que son tomadas de este periódico; en caso contrario se indicará.

7 En diciembre de 1952 se anuncia que don Pedro Rivas, empresario radiofónico en Aguascalientes, realiza gestiones con otros empresarios para instalar una antena retransmisora en el Estado, además, como accionista se contem- 
muy pronto esta iniciativa no es considerada viable. Don Pedro Rivas, empresario radiofónico, pionero en la ciudad de Aguascalientes, explica que comprendió que iniciar y mantener una televisora en provincia no sería posible debido a dos factores: el principal, la poca capacidad financiera de los anunciantes locales y, el escaso potencial para ofrecer entretenimiento que compitiera con la oferta que Telesistema Mexicano (TM) ya poseía como herencia del consorcio radiofónico XEW. ${ }^{8}$ De esta manera, don Pedro Rivas es protagonista, en nuestra ciudad, de las primeras trasmisiones en TV, pero sólo como aficionado y experimentador de esta posibilidad técnica.

En sus inicios, la TV se entrelazó con la vida social de Aguascalientes; se trasmitieron las fiestas o la coronación de la reina de la verbena abrileña. ${ }^{9}$ La iglesia aparece como el primer proveedor de eventos mediáticos, anunciándose la canonización del Papa Pío X y la misa de nochebuena oficiada por el Papa Pío XII. ${ }^{10}$ Después de cincuenta años se mantiene esta autoridad religiosa como protagonista de la pantalla televisiva. El Papa ejerce este papel antes que el presidente Adolfo López Mateos, que es la primera figura política presente en la televisión en esta ciudad. La Iglesia, además, antes que el Estado, se erige como juez y regulador de los contenidos televisivos y de los medios en general. En Aguascalientes, por ejemplo, aparece el comentario del obispo sobre las películas de estreno. ${ }^{11}$ En septiembre de 1957 anuncia el Vaticano que insta a todos los países a instalar oficinas eclesiásticas especiales para coordinar las actividades católicas en los campos del radio y la TV, denunciando los peligros latentes de sus contenidos cuando se emplean de manera licenciosa y no a favor de la ciencia, la justicia y la verdad. 12

plan las posibilidades de una televisora en el centro del país (31 de diciembre de 1952. Entrevista a don Pedro Rivas, 15 de noviembre de 2004).

8 Entrevista a don Pedro Rivas, loc. cit.

9 “Televisarán mañana una fiesta aquí", 6 de enero de 1956 y "Televisarán la ceremonia de coronación", 21 de abril de 1956. 29 de mayo de 1954 y 2 de diciembre de 1955.

11 "Monseñor Quezada alaba cinta El Judas", 30 de noviembre de 1955.

12 "Pide el Papa Pío XII estricta moralidad en la TV y en el radio", 12 septiembre de 1957. 
En la ciudad se había iniciado la compra de televisores, a pesar de que la señal de la programación del Distrito Federal se recibía de manera inestable desde el cerro del Zamorano, que se encuentra en los límites de Querétaro y Guanajuato. En enero de 1957, los distribuidores locales de televisores calculan que en Aguascalientes habría 500 televisores al finalizar ese año. ${ }^{13}$ Tres años después se daría cuenta de tres mil aparatos receptores instalados en los hogares. ${ }^{14}$ Precisamente en octubre de ese mismo año el gobierno del estado se suma a las iniciativas de los empresarios radiofónicos y distribuidores por instalar una antena retransmisora que permitiera mantener una señal estable. Se había comprometido a apoyar, junto con el capital privado, los gastos de instalación y anunciaba que gracias a sus gestiones, Aguascalientes se adelantaba con esta tecnología a otras ciudades cercanas, como Guadalajara. ${ }^{15}$ Con el Estado, se configuran los principales protagonistas de lo que sería una etapa que se prolongarían por casi diez años de conflictos por gestionar los recursos que este nuevo medio de comunicación exigía. Los distribuidores de televisores requerían de una señal de calidad para comercializar a mayor escala los aparatos receptores. Por otra parte, la población rápidamente había aceptado esta nueva tecnología, y después de la etapa del asombro inicial, paulatinamente exigió mayor calidad de la señal, horarios más amplios y diversificación en la programación. TM se encontraba en plena expansión de sus antenas repetidoras en el país y, en el caso de Aguascalientes, se adelantó a colocar la antena con poca experiencia para negociar los gastos con el gobierno del estado. Después, en Zacatecas, exigiría contar con la infraestructura técnica

13 “500 televisores habrá aquí al terminar el año", 31 de enero 1957. Según datos censales del INEGI, en 1950 la población total urbana y rural en Aguascalientes era de 188,075 personas.

142 de noviembre de 1960 . En 1960, la población total se incrementa a 243, 363 personas.

15 "Ingenieros de TM a requerimiento del Estado informan que realizarán pruebas preliminares ( 13 y 14 de octubre) para instalar una planta y antena de TV de gran alcance en Ags". 15 de octubre de 1957 y entrevista con el Ing. Roberto Martínez, 18 de abril de 2005. 
adecuada antes de realizar su propia inversión y enviar su señal. 16 TM coloca la antena retransmisora en el cerro de Los Gallos a finales de octubre de 1957, en condiciones precarias. No había un camino adecuado desde la carretera panamericana al cerro; sólo había una brecha de terracería, y el último tramo, en sus inicios, se recorría a pie o con burros, para transportar el diesel que proveía de combustible a la antena, debido a que no contaba con energía eléctrica. No había caseta para alojar los equipos de operación de la antena y sólo se cubrían con una lona, por lo cual estaban expuestos a las inclemencias del tiempo. Además, sólo había un aparato receptor con capacidad para recibir sólo un canal a la vez y sin posibilidad de ser repuesto en caso de alguna contingencia. ${ }^{17}$ Aun así, en noviembre de 1957 se anuncia la primera programación televisiva en el periódico, y se dispara la promoción y venta de televisores en la ciudad. ${ }^{18}$

A partir de esta fecha, la TV frecuentemente aparece como la noticia a ocho columnas en el diario, debido a las constantes fallas de la señal y a las exigencias de los telespectadores por reestablecerla, frente a los desacuerdos entre el gobierno, los distribuidores y TM por asumir los gastos que se generaban. TM aumentó sus cuotas de publicidad y pagaba los gastos de mantenimiento y el sueldo de su representante local, el Ing. Roberto Martínez, que lidiaba con los conflictos por restablecer la señal a pesar de la escasez de recursos. TM aseguraba que el gobierno no había cumplido los acuerdos iniciales. Tomó varios años para que finalmente se construyera un camino adecuado para llegar a la antena y la caseta para albergar el equipo. Los distribuidores gestionaban entre el gobierno y TM, que amenazaba con retirar la señal ante la falta de apoyo, y los consumidores que devolvían los recién adquiridos aparatos sin comprender que su inadecuado funcionamiento se debía a otros factores.

16 Entrevista con el Ing. Roberto Martínez, 16 de diciembre de 2004 y 18 de abril de 2005 .

17 Loc. cit.

18 "Publicamos desde hoy los programas de televisión. Programación", 23 de noviembre de 1957. Durante este año es muy notoria la cantidad de anuncios publicitarios promoviendo televisores. 
Paralelamente a los conflictos de origen económico y técnico, la TV despierta nuevas inquietudes entre la población. Surge el miedo a la nueva tecnología, argumentando que sus rayos podrían afectar la visión, lo cual se agudiza cuando durante el Congreso Internacional de Radiología que se lleva a cabo en la ciudad de México, donde se revela que la TV constituye un grave peligro para la vista. ${ }^{19}$ Además, la noticia de una mujer que muere por una descarga eléctrica al sacudir su aparato televisor genera alarma entre la población. ${ }^{20}$ Otra noticia que es motivo de escándalo en la ciudad, es la denuncia de la Procuraduría General de la República sobre el consumo y tráfico de enervantes en Televicentro. Figuras como Paco Malgesto, Manuel "El Loco" Valdés y Germán Valdés "Tintán" se encuentran involucrados. 21

Sin embargo, el debate principal que se genera en torno a la TV es la crítica a la mala calidad de sus contenidos. Desde finales de los cincuenta inicia la preocupación por lograr una legislación que reglamente y apoye el mejoramiento de la programación en beneficio de la niñez y la juventud; polémica que aún en nuestros días no se resuelve. Llama la atención un editorial de la época que además de hacer una crítica a la programación, critica, a su vez, a los detractores de la TV, que no tienen una comprensión amplia del medio como resultado de una sociedad comercial y superflua, y aclara que la TV no es la única causa de sus males. ${ }^{22}$ Paralelamente a este marco social de la llegada de la TV a Aguascalientes, existe la narrativa que surge del recuerdo de las familias, y cómo a lo largo de tres generaciones la TV se incorporó en su vida diaria.

En este sentido, pueden identificarse en la vida familiar tres momentos analíticos centrales en la trayectoria biográfica de la televisión. Primeramente, se da la etapa en la cual esta es un elemento innovador en la vida cotidiana de la provincia y un artículo de estatus; sin embargo,

19 "Despiden rayos X las pantallas de TV", 25 de julio de 1956.

20 "Un televisor Philips mató a conocida dama de Ciudad Madero, Tamaulipas. Cayó fulminada al sacudir el trágico aparato", 18 de agosto de 1959.

21 "Televicentro, guarida de mariguanos. Paco Malgesto, "Tintán”, "El Loco" Valdés, etc. Son adictos a la yerba", 6 de junio de 1959.

22 "La TV y los hechos de la vida", por Waldo Frank, 7 de marzo de 1960. 
rápidamente se instala como un objeto indispensable y común en la vida familiar de las mayorías. En segundo lugar, podría describirse una etapa de redefinición de aquella en torno a la TV; es una etapa que no puede delimitarse claramente, porque los cambios continúan; sin embargo, pueden señalarse las principales reconfiguraciones que la TV instaló en la vida familiar. Por último, se describe una etapa que se abre como el horizonte a futuro, y sin duda una veta muy importante para la agenda de investigación en el análisis de la recepción y el consumo televisivo; los cambios introducidos, principalmente por la tecnología digital, que posibilita la convergencia entre varios medios de comunicación, o intermedialidad, y las crecientes competencias adquiridas por las generaciones más jóvenes de usuarios, plantean un cambio cultural trascendente que sin duda debe analizarse más allá de las perspectivas apocalípticas, y más bien abordando su estudio en el sentido que señala Martín-Barbero (1999), como "nuevos modos de ver/leer", o como apunta Orozco (2006), como "interacciones entre las múltiples pantallas".

\section{LA INCORPORACIÓN DE LA TELEVISIÓN EN LOS HOGARES}

Antes de la llegada de la TV, podría decirse que la diversión de los niños y adultos se da en la calle. Se narran con nostalgia los juegos de los encantados, la roña, el pinaco, la pelota, y los patines. Otros espacios presentes son: el llano, en donde se jugaba beisbol y futbol, el cine en las matinés, los paseos al campo y a las huertas los domingos, e ir a la plaza principal, en donde jugaban los niños y se comía en los puestos. Pedir permiso para salir a sentarse a la banqueta, ver jugar a los niños y pasar a las personas era una de las diversiones de las jóvenes, o sentarse a bordar o tejer en la ventana para ver y ser vista. En casa se oía la radio, no como acompañante de otras tareas, sino como una diversión en donde la familia reunida escuchaba música, o las radionovelas, mientras las mujeres hacían labores a mano.

En los primeros encuentros con la TV, ésta se describe como un invento novedoso, un objeto de lujo que se vio, por primera ocasión, en los aparadores o en la casa del patrón o de los más ricos. En las pláticas cotidianas se comentaba sobre el nuevo cine, en donde en una pantalla 
se veían y oían los acontecimientos. Era sorprendente e inexplicable cómo podría ocurrir tal cosa. ¿Estarían las personas dentro del aparato? Más de un niño se asomó al interior buscando la explicación. Varios ancianos confiesan que cine se hacían a un lado cuando había balazos "por si las dudas"; al llegar la TV ya habían aprendido que no había peligro. De las casas de los ricos, la TV pasó a la de algún vecino, y en ocasiones, por buena voluntad, y en otras cobrando cinco o diez centavos, se permitía a los niños ver los primeros programas de Tarzán, caricaturas, cuentos o musicales.

De esta manera, la TV se compartía en espacios públicos, sobre todo en las clases y barrios bajos, en donde los recursos escasean. Los primeros dueños de televisores siempre tenían a niños viendo la TV desde la ventana; otros decidieron hacer negocio, cobrar algunos centavos por permitir ver su TV, e incluso vender dulces. Es contrastante cómo en las clases altas no se mencionó nunca el "pagar por ver", o permitir a otros ver sus televisiones; para ellos siempre fue un artículo para su uso en el espacio propio. Sin embargo, a pesar de las diferencias socioeconómicas, existe un punto en el cual coinciden: la sala. La primera TV, en la década de 1950, era un aparato de lujo, el cual había que exhibir y cuidar mucho.

La mayoría de las familias pronto pasan de concebir a la TV como un artículo de lujo, a uno indispensable en la vida familiar. Como se explicó, con la llegada de la TV a la ciudad se emprende, por parte, de los comerciantes, una gran promoción para aprovechar el nuevo mercado abierto por la innovación tecnológica, abriendo la posibilidad de su compra a través del sistema de pagos por plazos o en abonos. De pagar unos cuantos centavos por ver la TV en alguna casa ajena, la familia se organiza para lograr su primera compra. La televisión era un artículo caro; comprarlo, para la mayoría de las familias, significó un esfuerzo, pero también una gran satisfacción. Narran que una de las motivaciones para comprar la TV, fue que sus niños y jóvenes salían a verla a otros hogares, en los cuales a veces no se los permitían y llegaban llorando a casa; o se quedaban hasta muy noche viéndola, y eso preocupaba a los padres. Además de la presión ejercida por los niños y jóvenes por adquirir una $\mathrm{TV}$, estaba el propio deseo del adulto de entrar a la modernidad. Tal objeto en casa representó un insertarse 
en el progreso y estar conectado al exterior, aunque en los primeros contactos con la TV las familias señalan invariablemente que era vista como una opción innovadora en el entretenimiento familiar, aunque no estaba presente el carácter informativo, el género de las noticias, como lo será en los tiempos futuros. La mayoría de las familias recuerdan con cariño la compra de su primera TV y la relacionan con sucesos familiares significativos: nacimientos, bodas... Recuerdan el costo, entre tres y cuatro mil pesos, su carácter de mueble grande, de buena madera, y el lugar en donde lo ubicaron por primera vez, generalmente la sala o estancia principal. En las familias de menores recursos se logra comprar la primera TV cuando los hijos mayores trabajan; comprar su propia TV se considera un signo de independencia y logro económico. Paulatinamente, la TV se convierte en uno de los artículos básicos de compra antes de casarse y organizar el propio hogar, incluso es considerada uno de los regalos de bodas más adecuados. En la década de 1960, la TV pasa a ser parte los muebles y electrodomésticos básicos del hogar.23 De esta manera, la compra de la TV, además de ingresar a la modernidad, es un elemento indispensable para iniciar un hogar.

Los sujetos entrevistados, pertenecientes a la primera generación, vivieron la incorporación de la TV no sólo en la vida familiar, sino en la vida social de Aguascalientes. Sin embargo, aún dominaban, en los tiempos de ocio, los juegos en la calle para los niños. La TV se veía por las noches, y poco, dada la pobre oferta de programación de la época. En los inicios se veía con una programación común para toda la familia, el box, las corridas de toros, o los musicales; en torno a ella se reunían todos sus miembros, demás familiares y los vecinos. Para los adultos, la TV se convirtió en la posibilidad de una diversión de bajo costo, sobretodo para las clases trabajadoras: "la vida se hizo más ligera con la diversión de fácil acceso y barata que fue la TV".

23 Un matrimonio narra cómo antes de comprar su propia TV iban a verla a casa de sus padres, regresaban a casa en bicicleta, la esposa en los diablos, embarazada, durmiéndose, ya pasadas las diez de la noche. Habían programado comprar primero su mueble de recámara, pero ante las circunstancias decidieron comprar la TV. 
A la pregunta sobre cómo la TV ha mediado la visión del espacio público, es decir, la comprensión e interpretación de los eventos públicos, resaltó la información que este medio les proporcionó sobre los cambios sociales, la modernidad y la cultura del consumo mediático que actualmente prevalece. Son muy elocuentes los miembros mayores de cada familia, cuando narran su visión del mundo antes de la llegada de la TV. Los sucesos eran comprendidos principalmente a través de las pláticas de otras personas, de líderes de opinión o de sus padres, personas que tenía acceso al periódico o con mayor instrucción para comprender las noticias que eran dadas en la radio. Se percibían como "niños en el limbo", inocentes y ajenos a los problemas mundiales, aun las guerras eran interpretadas como más lejanas a su realidad que las contemporáneas, debido a que los medios les han otorgado un carácter tangible por la imagen en movimiento, y a la repetición y su continua presencia en las noticias. Varios ancianos comentaron que no pueden explicar con claridad la diferencia del impacto que significó “escuchar" sobre sucesos mundiales, a "verlos" incluso en el momento en que sucedían. Los eventos mediáticos que prevalecen en la memoria son la llegada del hombre a la Luna, el asesinato de Kennedy, y de manera más reciente, las giras del Papa Juan Pablo II. Uno de los entrevistados comentó: “La TV logró colocarnos en el tiempo". Se refiere a que antes se percibía predominantemente el acontecer del rancho, del barrio y de la pequeña ciudad; los sucesos lejanos parecían muy ajenos a la realidad inmediata. Ahora los medios han integrado lo inmediato y los sucesos que ocurren en lugares distantes como igualmente importantes.

\section{RECONFIGURACIONES EN}

\section{LA VIDA FAMILIAR A PARTIR DE LA TV}

La incorporación de la TV en la cotidianidad de la familia creó una dinámica de reconfiguraciones en la vida familiar tradicional, que no puede delimitarse con claridad debido a que es un proceso que se ha abierto y continuará con las nuevas tecnologías de comunicación e información que se instalan en la vida familiar; no desplazan a la TV, sino que se enlazan en las modalidades de su uso. Además, la TV se une a otras dimensiones externas que reconfiguran la vida familiar de manera 
permanente; sin embargo, en este apartado se dará cuenta de algunas de las principales situaciones familiares que se desplazan en su relación con la TV. Lo que acontece en la ciudad provinciana de Aguascalientes coincide en gran medida con otros estudios en la misma ciudad (Navarro, 2003; Padilla, 2004), en otras ciudades del país (Covarrubias, 1994; Guadarrama, 2000) e incluso en Latinoamérica (Barrios, 1993; Tufte, 1999), lo que permite corroborar hallazgos y contribuir a fundamentar el conocimiento en torno a la recepción televisiva y la vida familiar.

Uno de los desplazamientos más evidentes es el paulatino traslado de la TV a los espacios públicos, compartidos entre la familia y los vecinos, hacia la privacidad y el uso individual. La concepción de la TV como un medio que se comparte en público, ahora se sitúa en lo privado, como una tendencia observada, no sólo con relación al mayor nivel socioeconómico de las familias, que permite la compra de más televisores para el uso familiar, sino, además, en las familias de clases económicas más bajas, debido a la masificación comercial de esta tecnología. Aunque debe señalarse que esta tendencia es más clara en las familias que tienen la posibilidad de diversificar sus espacios en donde se ve la TV, y en la medida en que la vivienda no tiene esa posibilidad, la televidencia es necesariamente compartida. Sin embargo, sobretodo en el caso de las clases medias, y en adelante en la escala socioeconómica, la TV ha configurado sus propios espacios, surgiendo el concepto de " la sala TV", inexistente en el pasado, modificando el manejo de los espacios familiares: del protagonismo de la TV en la sala, pasó también al comedor, a la cocina, y sobre todo, actualmente, a la recámara. Paulatinamente la TV se convierte en un medio de uso personal, aún en las familias de escasos recursos. Comprar la TV para colocarla en la recámara es un logro importante, ya no de naturaleza familiar, como se explicó en sus inicios, sino ahora personal.

Es frecuente la denuncia sobre la afectación de la TV en la vida familiar, en el sentido de que ha desplazado los momentos en los cuales la familia conversaba; el ejemplo más claro es con relación a las comidas familiares. Sin embargo, en este estudio se corroboran los hallazgos de otras investigaciones (Covarrubias, 1994; Navarro, 2003; Padilla, 2004), en las cuales la carencia de comunicación familiar está ligada a otros factores, como los estilos y ejercicio de la autoridad en la familia; 
además, en algunas familias el ver televisión juntos es precisamente la ocasión en donde conversan sobre sí mismos y sobre sus preocupaciones vitales, incluso a partir de los contenidos televisivos. El problema de la fragmentación de la vida familiar debido a la TV, parece ser que no es por el hecho de no hablar mientras la ven juntos, sino precisamente al ya no verla juntos.

La concepción en torno a esta, como un aparato con horarios y programas específicos se desdibuja, la disciplina para los niños y jóvenes por el uso de la televisión, se debilita en la mayoría de las familias a través de las generaciones. En las entrevistas, las familias dan cuenta de que los cambios en la vida urbana han provocado que los juegos infantiles y la convivencia vecinal en las calles, por las tardes, se vuelvan cada vez más escasas, sobre todo entre las clases medias. La televisión se ha incorporado como "telón de fondo" de las actividades cotidianas de la vida familiar, no las ha desplazado, porque ahora se come, hace tarea, platica, cocina, plancha, incluso se hace ejercicio viendo TV.

Ver TV se diluye entre las actividades familiares, sin definir horarios y usos específicos; ya no es una actividad que acontece después de cumplir las tareas, salir a jugar, bañarse e incluso cenar; como comentan, era la costumbre en la vida familiar en las primeras épocas de la televisión. Además de la disciplina familiar, este cambio se debe a que, en sus inicios, los horarios y la programación televisiva era muy reducida, principalmente para los niños, y ahora las opciones en horarios y temáticas parece no tener límites. Para los niños de las familias contemporáneas la TV se vincula de manera estrecha con la vida familiar, de tal manera que no se concibe su cotidianidad sin ella.

La disputa por el "control" y la autoridad en torno a la TV es un tema importante en el hogar, dado que su uso va aparejado al manejo de la autoridad en la familia. Las relaciones de poder en esta, se ven claramente reflejadas en el manejo del "control" de la TV. En sus primeras épocas en la vida familiar, se seguía la línea jerárquica tradicional en el ejercicio del poder: primero el padre de familia, en su ausencia la madre, y posteriormente los hijos, de acuerdo a su edad. A través del tiempo esto se va trasladando hacia un mayor poder por parte de los jóvenes y niños, incluso, actualmente, son los niños y los 
jóvenes quienes principalmente se disputan el "control" por la TV, y se imponen incluso a los padres de familia, que generalmente han cedido en estos conflictos. La TV se duplica; además de la sala, en la recámara de los padres, en donde la autoridad paterna prevalece con cierta ambigüedad; sin embargo, en general, todas las televisiones en el hogar tienden a ser controladas por los hijos, y los padres deben negociar para verla. Al paso del tiempo, es evidente cómo el control de la TV, pasó a ser un dominio de los hijos; en ocasiones debido a la facilidad que tienen las nuevas generaciones para dominar las nuevas tecnologías. Además de la relación de la autoridad con los usos de la $\mathrm{TV}$, otra dimensión de esta temática es el papel que ha jugado esta en desdibujar los ámbitos, tradicionalmente separados, entre la adultez y la niñez. La creciente oferta en la programación, y el uso individual, en aislamiento y con mayor libertad de la TV, permite a los jóvenes y niños acceder a estilos de vida, contenidos e imágenes, antes reservadas sólo para los adultos. Pareciera ser que "la manzana prohibida" está disponible a todas horas, y en ocasiones, ningún ángel guardián la vigila; la democratización en el acceso a la información se ha traducido en cambios en el manejo de la autoridad familiar. Aún falta mayor reflexión e investigación en este terreno para definir el papel de la TV en los cambios familiares con respecto a la democratización de la información. En las familias entrevistadas existe una clara conciencia en torno a este tema, independientemente de los aspectos morales que, en algunos casos, sobre todo en la clase media, son muy importantes (Padilla, 2004). La preocupación se concentra, además de la exposición a contenidos "incorrectos", en el creciente desplazamiento de otras actividades lúdicas, de ocio y de relaciones interpersonales, e incluso de fuentes de aprendizaje consideradas más adecuadas, como la lectura, no sólo por la TV, sino la creciente oferta de medios de comunicación y tecnologías de información; sin embargo, no existen claras estrategias, de parte de los adultos, o de la familia en general, para asumir este desplazamiento y dar respuesta a ello.

Los cambios en la manera de ver televisión han significado también cambios en lo que se ve, de manera consecuente, como ya se explicaba, porque verla en familia, en los inicios de este medio, significaba ver programas precisamente de naturaleza familiar y que aún no segmen- 
taban de manera específica a las audiencias, por edad, género o estilo de vida. El gusto por la programación televisiva ha cambiado a través de las generaciones, en gran medida propiciado por las lógicas de la producción, que se han diversificado de manera impresionante. En los primeros años de trasmisiones televisivas, no se distinguían claramente los géneros, y los programas televisivos eran una ligera variación de los programas musicales de radio, principalmente de la tradicional XEW. Paulatinamente, al incrementarse la oferta programática por parte de la TV, se inicia la distinción entre géneros: deportes para los hombres, telenovelas para las mujeres, y musicales y comicidad para los horarios familiares. Actualmente la oferta se ha diversificado y complejizado de manera exponencial; prácticamente existen programas específicos para cada miembro de la familia.

Consideramos de utilidad dar cuenta de los principales géneros y programas que han prevalecido en la memoria familiar. Los miembros mayores de 65 años mencionaron los siguientes: el programa de "Los cuentos de Cachirulo" es una constante en las memorias de las audiencias; las películas de la época de oro del cine mexicano y sus artistas más relevantes; los programas de corte policíaco como "La ley del revólver", "Los intocables"; de los deportes, el box sigue en el recuerdo; de las novelas se mencionaron a "Simplemente María", "Los ricos también lloran"; los programas familiares como "Viruta y Capulina" y "El Chavo del Ocho"; además de los programas, se siguen mencionando algunos patrocinadores como Vanart, Coca Cola, Pepsi, Raleigh y Choco Milk. En el caso de las personas entre 65 y 35 años comentaron que recuerdan con mucho agrado las series norteamericanas como "El planeta de los simios", "Tarzán", "Bonanza" y "Señorita Cometa", este de origen japonés; los programas musicales con las primeras estrellas del rock, como Angélica María y César Costa; las telenovelas; "Los cuentos de Cachirulo"; "El Chavo del Ocho" y "Siempre en domingo" como los programas que reunían a toda la familia; de concursos "Sube Pelayo Sube" o "Chabelo"; los cómicos como el de "Viruta y Capulina", el "Show de 'El Loco' Valdés"; y en los deportes aparece el futbol soccer y el americano. Las generaciones actuales tienen presentes los reality shows, como "Big Brother" y "La Academia", programas de concursos como "Cien mexicanos dijeron", telenovelas y las noticias. 


\section{LA TV Y LAS NUEVAS TECNOLOGÍAS \\ DE INFORMACIÓN}

Estas se integran de diferentes maneras a lo largo de las generaciones. Es muy interesante el papel que la TV ha tenido en la vida de las personas de mayor edad, sobre todo porque en su trayectoria vital pueden valorarse los cambios y la biografía de esta tecnología. De aparato que representaba la modernidad pasó a ser un medio de entretenimiento, y ahora, en su vejez, un medio de información y de advertencia en torno a los peligros de la actualidad. La TV les ofrece los argumentos para validar que "todo tiempo pasado fue mejor". Además, para las personas de la tercera edad, las acompaña en su estilo de vida más tranquilo, en el cual disponen de mayor tiempo para estar frente a ella. En cuanto al lugar que ocupa con relación a otros medios y tecnologías, se puede afirmar que las personas mayores de 65 años mantienen su relación con el periódico, sobre todo los hombres; la radio se ha desplazado de ser uno que se escuchaba en familia a ser uno que se escucha mientras se realizan otras actividades; sin embargo comentan que ya no escriben cartas, ni bailan con la sinfonola, tampoco se toca el piano o se canta en la casa como entretenimiento. ${ }^{24}$ Los nuevos medios como la TV por cable, el DVD, la computadora y la internet los rebasan porque, como dicen, "no le saben mover"; parecen aceptar con tranquilidad que ya no son medios de comunicación de su era y ven con agrado y asombro la capacidad de sus nietos y los jóvenes para comprenderlos y manejarlos. Comentaron que les incomoda la poca vigencia de la tecnología; recordaron la satisfacción que representaba en algunas familias tener una cámara de cine y un proyector para ver las escenas y sucesos familiares, ahora se debe cambiar de formato para verlas y aun el video da paso al DVD. ${ }^{25}$ Con sabiduría explican que no se logró que la TV desplazara al radio o al cine, sino que "cada uno encontró su lugar en la vida de las personas".

En la segunda generación, la TV adquiere el simbolismo de una mejora económica y social, la incorporación a la vida citadina, dejando los patrones rurales. También representa el tránsito del entre-

24 Estos recuerdos están presentes sobre todo en familias de clases alta y media.

25 Estas percepciones asimismo pertenecen a los estratos alto y medio. 
tenimiento en los espacios vecinales y públicos al privado. La TV es una excelente opción, cómoda y barata para entretenerse después de las jornadas de trabajo. Comparte sus vínculos con la cotidianidad de la radio, ligándose más con el entretenimiento, y dejándole a esta el papel de acompañante del trabajo y los quehaceres. Con respecto a otras tecnologías, existe la añoranza por los radios, las televisiones y las consolas tipo mueble, grandes y de mayor belleza estética; ahora todo es más pequeño, práctico y desechable. Añoran los discos que se intercambiaban y coleccionaban, y lamentan que ya no se escriban cartas. Ahora la internet ha sustituido la comunicación personal a distancia, y les parece que se perdió el sello personal de una carta manuscrita. En sus hogares, la TV convive aún con la radio y el periódico, y más recientemente con y el DVD, lo cual va en aumento, además de los celulares, la computadora, la internet y las agendas electrónicas. Han fomentado la compra de nuevas tecnologías de información porque comprenden sus ventajas, y las utilizan con cierta dificultad, sin embargo, consideran no pueden competir con sus hijos en sus habilidades para aprovecharlas.

En la tercera generación, la TV ha estado siempre presente en sus vidas y la relación con la TV se complejiza; ya no se trata de "la televisión de la casa", hay televisiones en todas partes, en la cocina, en el comedor, en la sala de TV y en las recámaras, y se integra de manera muy estrecha a la vida cotidiana, de tal manera que no se concibe ésta sin la TV.26 El grado de habilidad y competencias en torno a la TV se incrementa de manera vertiginosa; cada vez más los niños más pequeños comprenden y manejan sus géneros, formatos y posibilidades. Además, sin importar el nivel económico de la familia, la TV junto con el radio, no son ya las únicas tecnologías familiares, se convive con las video caseteras, los videojuegos, y los nuevos formatos DVD para ver películas, aunque esta generación tiene una clara preferencia por el cine. La música es vital para los menores de 35 años y se maneja en los aparatos de sonido en CD y digitalmente vía reproductores de música, ipods, computadora e internet. La computadora es una herramienta indispensable para quiénes estudian y un nuevo compañero de

26 Esto se da incluso en las familias de escasos recursos. 
juegos para los niños y los jóvenes, y aún cuando la internet no es un servicio con el que cuenten todos los hogares, en esta generación se acude a negocios que lo ofrecen o tienen acceso a él en el trabajo o en la escuela. La oferta programática en TV se multiplica a través de la TV por paga y la percepción audiovisual de esta generación también. No es necesario que perciban un relato o información de manera lineal y en secuencia; las narrativas se perciben en varias dimensiones, traslapadas y fragmentadas. Se ve TV, con el control en mano, varios programas a la vez, se trabaja con un procesador de textos, se chatea y escucha música al mismo tiempo, la telefonía se desdobla en texto e imágenes. La televisión se utiliza con otros medios a la vez y además se realizan actividades paralelas. No necesariamente se sientan o acuestan a ver TV; es un telón de fondo que da vida y calor de hogar al espacio, sin ella se siente vacío y soledad. Los jóvenes y los niños ya no requieren juguetes; lo lúdico, la información y las relaciones con otros se dan en la convergencia digital y audiovisual. Definitivamente esta generación no concibe su vida sin la TV y, cada vez más y de manera acelerada, sin varias de las nuevas tecnologías de información.

\section{CONCLUSIONES}

De los hallazgos de esta investigación, surgen varias reflexiones y temas, que a su vez requieren mayor análisis e interpretación; a partir de ellos se plantean nuevas preguntas y una agenda diversificada para su estudio. De la historia social de la TV surge la interrogante sobre el papel del Estado como previsor y regulador de la iniciativa privada y los intereses económicos. En este caso actuó de manera improvisada y tardía ante las decisiones de los actores empresariales. Por otra parte, se narra desde la mirada de la provincia cómo se dieron los mecanismos que permitieron la consolidación del monopolio televisivo en México. En la ciudad de Aguascalientes, la TV se sitúa en el ámbito de lo social y el entretenimiento, reaccionando ante ella primero el discurso religioso y apropiándose de sus posibilidades antes que el político. Recuperando la historia de la TV, se comprende cómo el espacio público cambió su configuración; la población se contempla desde otra perspectiva, como telespectadores o audiencias que inser- 
tan nuevos debates, con la exigencia de calidad y estabilidad técnica de la señal, un incremento en los horarios y una programación cada vez más diversificada, se dispara el comportamiento de las televisoras comerciales y su carrera por los ratings. El surgimiento de la audiencia también incorpora las inquietudes por los daños y consecuencias a la salud y a la moralidad, con relación al ver TV, y un debate más trascendente, que parece resolverse actualmente, de manera desafortunada, sobre cómo legislar no sólo los contenidos televisivos, sino en torno a los intereses económicos y de empresa que los producen. La capacidad de la publicidad se expande y con ella la manera de comprender a las audiencias como un mercado diverso, segmentado, y en permanente crecimiento.

La llegada de la TV a la vida familiar no significó necesariamente por sí misma un cambio en la vida cultural, sino que manifestó simbólicamente el cambio que varios factores gestaron en la segunda década del siglo XX. La familia incorporó el concepto de modernidad y progreso en la adquisición de tecnologías para el hogar, en donde la TV, junto con otros electrodomésticos, formó parte de los objetos básicos para iniciar un nuevo hogar. El entretenimiento y el ocio adquirieron una nueva modalidad, compartida y social en los primeros años televisivos, y paulatinamente adoptaron un carácter individual y selectivo ante las nuevas ofertas de la TV temática, y la expansión de la internet en los hogares en los inicios del siglo actual. El espacio público y la información se vuelven accesibles y compartidos, desdibujando campos de poder manejados por adultos, maestros o líderes de opinión, y paradójicamente las relaciones vecinales y de comunidad se alejan con relación a la presencia mediática del espacio cosmopolita. Por último, una temática de interés que se perfila es que la competencia de lectura lineal televisiva se desdibuja ante las nuevas competencias de lectura multidimensional e intermedial que las nuevas generaciones manifiestan en sus usos, no sólo de la TV, sino de las nuevas tecnologías de la información. Se abren desafiantes e impensables estos nuevos horizontes si los comparamos con la ingenuidad mostrada en una fotografía de la página de sociales de un periódico local, en donde una joven socialité posaba frente a su recién adquirido televisor. 


\section{Bibliografía}

ANG, Ien, (1996) Watching Dallas: soap opera and the melodramatic imagination. Great Britain: Routledge.

ApPAdURAI, Arjun (ed.), (1991) La vida social de las cosas. Perspectiva cultural de las mercancías. México: CONACULTA/Grijalbo.

BARRIOS, Leoncio (1993) Familia y televisión. Venezuela: Monte Ávila Editores Latinoamericana.

Bourdieu, Pierre (1984) Distinction. A social critique of the judgement of taste. Trad. R. Nice, Cambridge: Harvard University Press.

CORNER, J. (2003) "Finding data reading patterns, telling stories: issues in the historiography of television", Media, Culture \& Society. Vol. 25, London: SAGE.

COVARRUBIAS, Karla, Angélica Bautista, y Bertha Uribe (1994) Cuéntame en que se quedó: La telenovela como fenómeno social. México: Trillas.

CRAWFORD, P. y S. Hafsteinsson (1996) The construction of the viewer. Media, ethnography and the anthropology of audiences. Denmark: Intervention Press.

DAHL, Hans Fredrik (1994) "The pursuit of media history", Media, culture and society. Vol. 16, number 4, october, London: SAGE.

GARCÍA CANCLINI, Néstor (coord.) (1993) El consumo cultural en México. México: Consejo Nacional para la Cultura y las Artes.

GONZÁLEZ, Jorge A. (1998) "Historias de familias entre el tiempo histórico y el tiempo biográfico: estrategias, objeto y método" en Valenzuela, J. y Salles, V. (coord.) Vida familiar y cultura contemporánea. México: CONACULTA.

GÓMEZ MOMPART, Josep Lluís (coord.) (1995) "Metodologías para la historia de la comunicación social”, I Encuentro de la asociación de historiadores de la comunicación. España: AUB, Bellaterra.

GUADARRAMA, Luis Alfonso (2000) Dinámica familiar y televisión. Un estudio sistémico. México: Universidad Autónoma del Estado de México.

GUBERN, Román (2000) El eros electrónico. Madrid: Taurus.

JACKS, Nilda (2001) "Historia de familia y etnografía, procedimientos metodológicos para un análisis integrado”, en Orozco, G. (comp.) 
Recepción y mediaciones. Casos de investigación en América Latina. Argentina: Grupo Editorial Norma.

JENSEN, Klaus Bruhn (1995) "El análisis de la recepción: la comunicación de masas como producción social de significado" en Jensen y Jankowski, Metodologías cualitativas de investigación en comunicación de masas. Barcelona: Bosch/Routledge.

LULL, James (1992) "La estructuración de las audiencias masivas", Diálogo de la Comunicación. núm. 32,. Lima: FELAFACS.

MARTíN-BARBERO, J. (1987) De los medios a las mediaciones. Comunicación, cultura y hegemonía. Barcelona: Gustavo Gili.

- y G. Rey (1999) Los ejercicios del ver. Hegemonía audiovisual y ficción televisiva, Barcelona: Gedisa.

- (2001) "Deconstrucción de la crítica: nuevos itinerarios de la investigación”, en Vassallo de Lopes, M. y Fuentes Navarro, R. Comunicación. Campo y objeto de estudio. Perspectivas reflexivas latinoamericanas. México: ITESO, UAA, UdeC, UdeG.

MATA, Cristina (2001) "Interrogantes sobre el público", en Vasallo de Lopes, I. y Fuentes, R., en Comunicación campo y objeto de estudio. Perspectivas reflexivas latinoamericanas. México: ITESO/UAA/ UEDC/UdeG.

MOORES, Shaun, (1996) Interpreting audiences. The etnography of media consumption, London: SAGE.

MORLEY, D. (1986) Family television: Cultural power and domestic leisure. London: Routledge.

NAVARRO, Ana María (2003) La interacción entre las familias y la televisión. Un estudio en Aguascalientes. México: UAA.

Nightingale, V. (1999) El estudio de las audiencias. Barcelona: Paidós.

OROZCO, Guillermo (2007) Un mundo de visiones. Interacciones de las audiencias en múltiples escenarios mediáticos y virtuales. México: ILCE.

- (2006) Al filo de las pantallas. México: en prensa.

- (2000) "Televidencias, una perspectiva epistemológica para el análisis de las interacciones con la televisión" en Orozco, G. (coord.) Lo viejo y lo nuevo. Investigar la comunicación en el siglo XXI. Madrid: Ediciones de la Torre. 
- (1994) "Recepción televisiva y mediaciones. La construcción de estrategias por la audiencia" en Orozco, G. (coord.) Lo viejo y lo nuevo. Investigar la comunicación en el siglo XXI. "Televidencia. Perspectivas para el análisis de los procesos de recepción televisiva”. Cuadernos de comunicación y prácticas sociales, núm. 6 , México: Universidad Iberoamericana.

PADILlA, Rebeca (2004) Relatos de telenovelas. Vida, conflictos e identidades. México: UdeG/UAA.

SEITER, Ellen (1999) Televisión and the new media audiences. Nueva York: Oxford Television Studies.

SPIGEL, Lynn, (2001) "Media homes: then and now", special issue Television and cultural studies, International Journal of Cultural Studies. Vol. 4 number 4 december, London: SAGE.

THOMPSON, John B. (1998) Los media y la modernidad. Una teoría de los medios de comunicación. Barcelona: Paidós.

TUFTE, Thomas (1999) "Televisión fiction, audience consumption and social change", Consuming audiences. Denmark: Hampton Press.

VAN ZOONEN, Liesbet y Jan Wieten (1994) "It wasn't exactly a miracle: the arrival of television in dutch family life", Media, Culture and Society. Vol. 16, núm. 4, octubre, London: SAGE.

VASSALlO, M., de Lopes (1995) "Recepción de medios, clases poder y estructura. Cuestiones teórico-metodológicas de investigación cualitativa de la audiencia de los medios de comunicación de masas". Comunicación y Sociedad. Núm. 24. México: Universidad de Guadalajara.

YOUNG, Mei Ling (1996) "El análisis de las historias de los hogares", Estudios sobre culturas contemporáneas. Época II, vol. 11, núm. 3, junio. México: Universidad de Colima. 